\title{
Variation of Brachial Artery And Its Branching Pattern
}

\author{
Sathialakshmi,V, Udaykumar, Christilda Felecia, Sujatha,N., SwayamJothi \\ .S.HemanthKommuru. \\ ShriSathyaSai Medical College \&Research Institute,Ammapettai, Kancheepuram District
}

\begin{abstract}
Brachial approach isgaining importance in cardiac catheterisation because of early ambulation and discharge. Accurate knowledge of this major artery of the arm in relation to its course and particularly of their variation of branching pattern is of considerable practical importance.

To study the brachial artery and its branching pattern 40 upper limb specimens from 20 adult cadavers were utilized. In 5\% cases brachial artery bifurcated above the intercondylar line, in 90\% cases below the intercondylar line and in 5\% at intercondylar line.Superficial brachial artery was present in 2 cases (5\%).Profundabrachii artery arose fromthe posterior circumflex humeral artery in $2.5 \%$, as abranchfrom III part of the axillary artery in $2.5 \%$ and along with Superior ulnar collateral artery as a common trunk in 5\%. Profunda brachii arose as 2 separate branches in 2.5\%.Superior ulnar collateral artery was arising as a common trunk with profounda brachial artery in5\%, as a branch of profunda brachii in 5\%. High origin of ulnar artery was observed in 5\% of limbs. 5\% specimens showed high origin of radial artery.
\end{abstract}

Key words: Brachial artery, Profundabrachii artery Superior ulnar collateral artery

\section{Introduction}

Striking variations in origin and course of the principal arteries of the upper extremities have long received the attention of anatomists and surgeons. Nowadays cardiologists and radiologists are utilizing the brachial artery with increasing frequency for catheter based diagnostic and therapeutic intervention procedures. It is gaining importance because brachial approach allows early ambulation and discharge.

Aim

To study the variations and branching pattern of Brachial artery.

\section{Materials \& Methods}

Brachial artery was studied in 40 upper limb specimens from 20 adult cadavers (14 males, 6 females).

The following parameters were observed:

1. Length of the brachial artery

2. Point of bifurcation in relation to intercondylar line

3. Variations in branches of brachial artery - Profundabrachii, superior ulnar collateral artery, nutrient artery of the humerus, inferior ulnar collateral, terminal branches.

Bifurcation of the brachial artery-

\section{Observations}

36(90\%) specimens bifurcated below the intercondylar line. In $2(5 \%)$ specimens the bifurcation was above the intercondylar line (Fig.1) and in the remaining $2(5 \%)$ it was at the intercondylar line (Fig.2) (Table - II).The average length of the brachial artery was $21.5 \mathrm{cms}$. In the present study out of 40 specimens, 11 specimens were less than the average length $21.5 \mathrm{cms}(28 \%)$ and in 29 specimens more than the average length (72\%).(Table-I).

Profunda brachii arterywas arising from the posteromedial side of the brachial artery in 35 (87.5\%) specimens. In 2 specimens (5\%) the profunda brachii artery and superior ulnar collateral artery arose as a common trunk(Fig:3), in 1 specimen (2.5\%) it arose from the posterior circumflex humeral artery(Fig : 4) and in 1 specimen (2.5\%) arose from the axillary artery(Fig: 5).In 1 specimen the profundabrachii arose as 2 separate branches.

The superior ulnar collateral arteryarose from the brachial artery in 36(90\%) cases, in $2(5 \%)$ specimens from a common trunk with profunda brachii artery (Fig.3) and in 2(5\%) specimens arose as a branch of profunda brachii.

In the present study the high origin of radial artery(superficial brachial artery) was seen in 1 specimen (Fig.6) and the high origin of ulnar artery(superficial brachial artery) was observed in 1 specimen(Fig.7). In $2.5 \%$ ulnar artery originated from the third part of the axillary artery (Fig: 6) and in $2.5 \%$ the radial artery arose from the brachial artery just below that teresmajor tendon (Fig.7). 


\section{Discussion}

Miller (1939) and J.A.Keen (1961) reported bifurcation of the brachial artery above the intercondylar line varies from $0.7 \%$ to $15.0 \%$. In the present study, in $5 \%$ cases brachial artery bifurcated above the intercondylar line, and in 5\% brachial artery bifurcated at the level of intercondylar line.Charles et al. (1931) specify 7 types of origins of arteria profunda brachii and in the present study. we observed four different types of origins. The origin of the profunda brachii from the common trunk with superior ulnar collateral artery showed5\% and originating from the axillary artery was found to be $2.5 \%$ in the present study which coincides with Patnaiket al. (2002). Profunda brachii originating from the posterior circumflex humeral was found to be 2.5\% which almost coincides with Charles et al. (1931).

According to Patnaiket al. (2002) superior ulnar artery arisingfrom brachical artery in $96 \%$ In the present study it was $90 \%$.In the present study 5\% specimen showed high origin of radial artery, which almost coincides with J.A.Keen. High origin of ulnar artery was observed in 5\% of casesin the present study, which was not mentioned in any of the previous studies.In the present studythe presence of superficial brachial artery formed 5\%, which coincides with the study of Linelle\&Poirier .

\section{Conclusion}

Brachial artery is used in diagnostic angiography, cardiac catheterisation for angioplasty, carotid stenting, transbrachial access for endovascular renal artery intervension, embolectomy through arteriotomy.The superficial radial artery and the superficial ulnar artery have been encountered during elevation of the radial forearm flaps The existence of the superficial radial artery implies the absence of the normal radial pulse at the wrist level. Apart from the above mentioned procedures, accidental intra arterial injections, ligation of artery instead of vein have been reported. In order to avoid all these catastrophies accurate knowledge of this major arterial conduit in relation to its course and particularly of their variationswill be definitely helpful and useful to the clinicians of their respective fields.

\section{References}

[1]. Miller, R.A. (1939): Observations upon the arrangement of axillary artery \& brachial plexus. American Journal of Anatomy 64: 143163

[2]. Keen, J.A (1961) : A study of arterial variations in the limbs with special reference to symmetry of vascular pattern. American Journal of Anatomy 108: 245-261

[3]. Charles, C.M; Pen, L; Holden, H.F; Miller, R.A. \& Elvis, E.B. (1931) : The origin of the deep brachial artery in American White \& American Negro males. Anatomical Record $50:$ pp 299-302

[4]. Patnaik, V.V.G. Kalsey, G; SinglaRajan, K. (2001a) : Trifurcation of Brachial artery - a case report. Journal of the Anatomical Society of India 50(2) : 163-165

[5]. Patnaik, V.V.G. Kalsey, G; SinglaRajan, K. (2001a) : Trifurcation of Brachial artery - a case report. Journal of the Anatomical Society of India 50(2) : 163-165.

[6]. Linell, E.A. (1921) : The distribution of the nerves in upper limb with reference to variability \& their clinical significance. Journal of Anatomy 55: p.79.

[7]. Poirier, P. Traite de Anatomie Humans Vol. II Battaille\& Co. Paris. pp 756 (1886)

TABLE- I

Length of Brachial Artery AVERAGE LENGTH : $21.5 \mathrm{CM}$

\begin{tabular}{|l|c|c|}
\hline \multicolumn{3}{|c|}{ AVERAGE LENGTH : 21.5 CM } \\
\hline VARIABLE & SPECIMENS IN NUMBER & PERCENTAGE \\
\hline Less than $21.5 \mathrm{cms}$ & $\mathbf{1 1}$ & $\mathbf{2 8 \%}$ \\
\hline More than $21.5 \mathrm{cms}$ & 29 & $\mathbf{7 2 \%}$ \\
\hline
\end{tabular}

Table - II

Point Of Bifurcation In Relation To TheIntercondylar Line

\begin{tabular}{|l|l|l|}
\hline DESCRIPTION OF BIFURCATION & NO.OF SPECIMENS & PERCENTAGE \\
\hline Below the Intercondylar line & $\mathbf{3 6}$ & $\mathbf{9 0 \%}$ \\
\hline Above the Intercondylar line & $\mathbf{2}$ & $\mathbf{5 \%}$ \\
\hline AT the Intercondylar line & $\mathbf{2}$ & $\mathbf{5 \%}$ \\
\hline
\end{tabular}

Fig 1: Bifurcation Of Brachial Artery Above The Intercondylar Line 


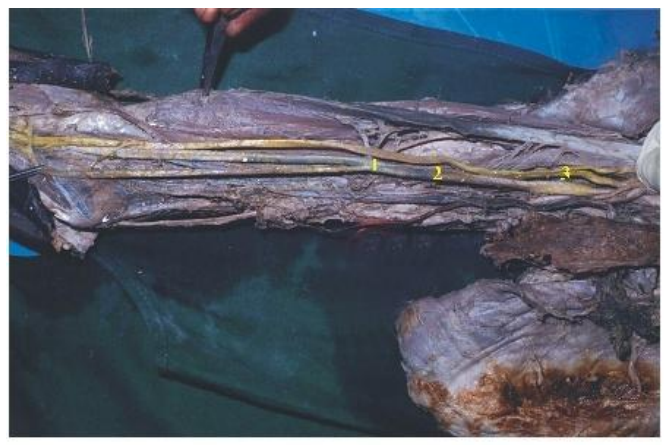
1. POINT OF BIFURCATION OF BRACHIAL ARTERY
2. BRACHIAL ARTERY

3. MEDIAN NERVE

Fig 2:Bifurcation Of Brachial Artery At The Intercondylar Line

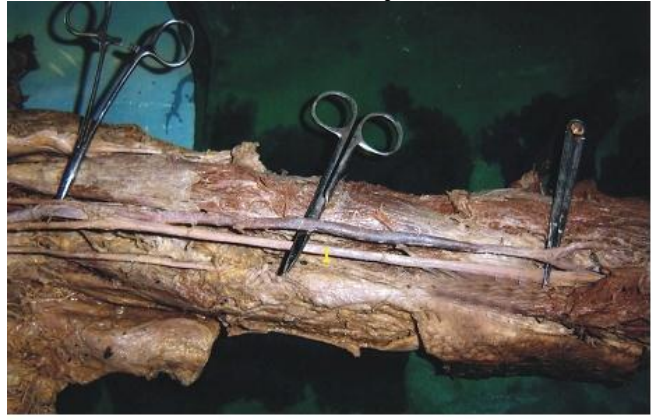

1. POINT OF BIFURCATION OF BRACHIAL ARTERY

Fig 3:Origin Of Superior Ulnar Collateral Artery From Common Trunk With Profunda

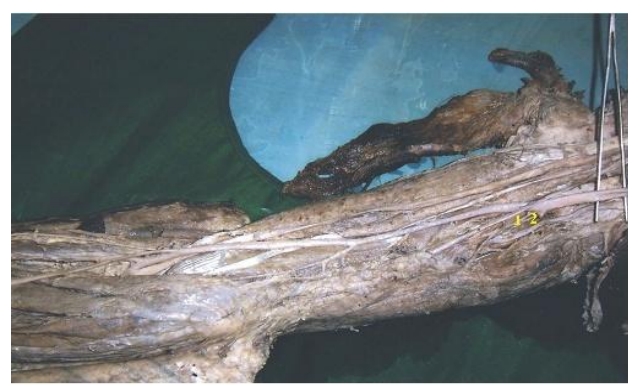

1. SUPERIOR ULNAR COLLATERAL ARTERY

2. PROFUNDABRACHIIARTERY

Fig: 4 ProfundaBrachiiFrom The Posterior Circumflex Humeral Artery

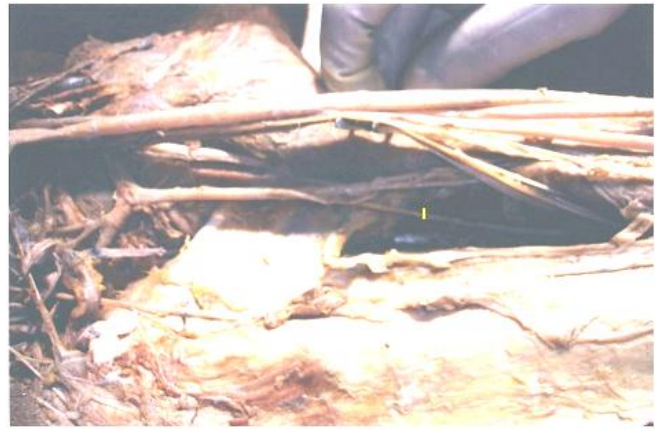

Fig :5PROFUNDABrachii From THE AXILLARY ARTERY

1. Profunda brachii artery 


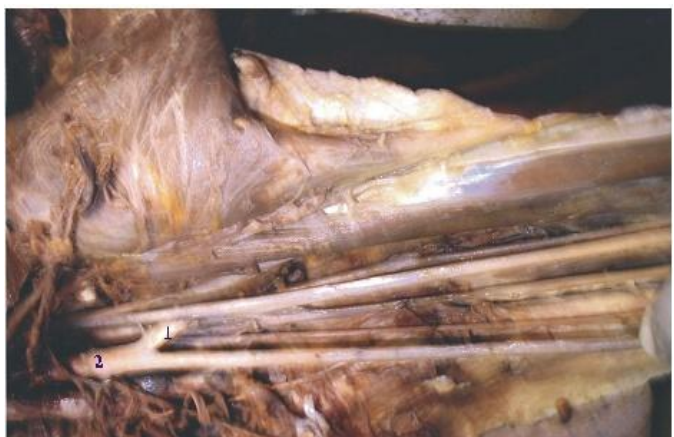

1. Profunda brachii.,

2. 2. Axillary artery

Fig 6: High Origin Of Ulnar Artery

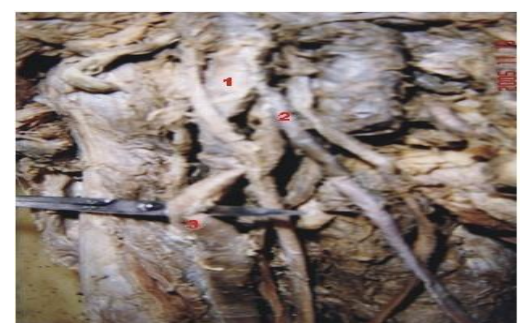

1. AXIILARYARTERY

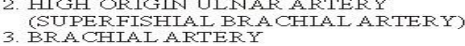

Fig 7: HIGH Origin Of Radial Artery

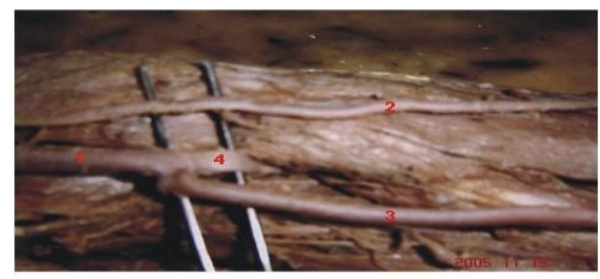

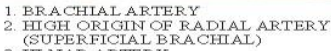

3. ULINAR ARTERY 